\title{
The Future of Respiratory Care: Results of a New York State Survey of Respiratory Therapists
}

\author{
Stephen G Smith MPA RRT, Lisa M Endee MPHC RRT-SDS RPSGT, Lisa A Benz Scott PhD, \\ and Pamela L Linden PhD
}

\begin{abstract}
BACKGROUND: In the current health-care environment, respiratory care may need to make significant changes to academic preparation and clinical practice. The purpose of this research was to assess current needs of respiratory therapists (RTs) in New York State and to understand how RTs perceive their future clinical and academic roles. METHODS: This study employed a descriptive, cross-sectional non-experimental design. Between October and December 2014, a 32-item online survey was distributed via e-mail to the 2,170 members of the New York State Society of Respiratory Care. Descriptive statistics were used to summarize responses, and bivariate analyses were assessed using Kruskal-Wallis and Mann-Whitney U tests. RESULTS: The response rate was $22 \%$ and resulted in $\mathbf{4 3 5}$ valid surveys returned. Seventy percent of $\mathbf{4 1 5}$ respondents agreed that the practice of respiratory care is at risk of losing practitioners. The most important incentive for retention of practitioners in the field was professional growth and an expanded scope of clinical practice. Specifically, the most important of these roles was gaining the ability to assess patients, develop a plan of care, and receive reimbursement for services. Sixty-four percent of 415 respondents strongly agreed that the minimum academic standard for RTs should be raised to the baccalaureate level. Of 415 respondents, the majority (78\%) agreed that it is important for therapists to remain in the profession and to be an active member of the American Association for Respiratory Care $(\mathbf{8 3} \%)$. CONCLUSIONS: These data are useful to the profession, notably for academic programs that must meet the need for a more highly prepared and skilled workforce. The findings emphasize that viability of the profession in the current health-care environment calls for the evolution of a more autonomous RT who can be reimbursed for services and obtain salaries that are competitive with other health professions. Key words: respiratory therapist; respiratory therapy technician; scope of practice; reimbursement; academic standard; clinical role; clinical ladder; paradigm change; out-patient care; healthcare environment. [Respir Care 2017;62(3):279-287. () 2017 Daedalus Enterprises]
\end{abstract}

\section{Introduction}

With the recent focus on outcomes-based medicine in the current health-care delivery model, the health profes-

\footnotetext{
Mr Smith and Ms Endee are affiliated with the Respiratory Care Program, Dr Benz Scott is affiliated with the Program in Public Health, and Dr Linden is affiliated with the Occupational Therapy Program, Stony Brook University School of Health Technology and Management, Stony Brook, New York.
}

Mr Smith and Ms Endee presented a version of this paper at the Converging Science Summit, held April 27, 2015, at Stony Brook University, Stony Brook, New York.

The authors have disclosed no conflicts of interest. sions will need to reevaluate the roles of their clinicians and the future needs of their profession. According to Barnes et al, ${ }^{1}$ advanced innovations in medicine and technology and a new emphasis on chronic disease management will have an effect on all healthcare disciplines. As a result of these changes, the profession of respiratory care must evolve to meet the requirements of the future clinical workforce.

\footnotetext{
Correspondence: Stephen G Smith MPA RRT, Stony Brook University School of Health Technology and Management, Respiratory Care Program, Health Science Tower, Level 2, Rm 441, Stony Brook, NY 11794 8203. E-mail: stephen.smith@stonybrook.edu.
}

DOI: $10.4187 /$ respcare. 04768 
Respiratory therapists (RTs) comprise a critical sector of allied health care,$^{2}$ and the number of RTs continues to

\section{See the Related Editorial on Page 384}

grow. ${ }^{3}$ A 2014 nationwide survey by the American Association for Respiratory Care (AARC) found that an estimated 172,921 RTs were issued licenses to deliver respiratory care in the United States, 19\% more than a 2009 survey. ${ }^{4}$ In New York State there were 5,433 RTs and 1,050 respiratory therapy technicians licensed in $2014 .{ }^{5}$

Traditionally, the majority of RTs are employed in inpatient hospital settings. Emergency departments and intensive care units in hospitals are the primary settings for the majority of RTs according to a report by the Center for Health Professionals at the University of California. ${ }^{2}$ The 2014 AARC Human Resource study ${ }^{4}$ reported nearly identical findings, with $74.9 \%$ of therapists working their primary job at an acute care hospital. However, with health care expanding from acute to chronic care, there is a strong impetus to manage patients on an out-patient basis. The Affordable Care Act seeks to reduce costs, prevent hospital readmissions, and increase patient education and selfmanagement. The importance of the RT in the prevention and management of chronic conditions and as part of a health-care team must not be underestimated.

In 2007, the AARC established a task force to identify changing roles and responsibilities of the RT. The task force reported that enhancing the quality of patient care delivered by more independent RTs, while at the same time lessening costs, will be an important force to improve healthcare delivery. ${ }^{1}$ The report described the need for a more competent practitioner with a strong knowledge of evidence-based medicine and the ability to effectively participate in collaborative health-care teams to help promote management of cardiopulmonary disease. ${ }^{1}$ Additionally, the task force anticipates that the future roles of RTs will be more clinically autonomous, providing respiratory care services at both the bedside and in the outpatient arena. ${ }^{1}$ The report stated that RTs of the future will need to possess the skills to properly assess patients in both in-patient and out-patient settings, including the home; to recommend and discontinue therapy; and to contribute to successful patient outcomes, including reduced lengths of stay and fewer preventable hospital admissions. RTs play a critical role in the management of patients with cardiopulmonary diseases and can have a significant impact on improving outcomes. There is some evidence that case management by RTs results in significant reductions in the duration of invasive and noninvasive ventilation and hospital days for patients with respiratory infections, asthma, and COPD. ${ }^{2,6-8}$

\section{QUICK LOOK}

\section{Current knowledge}

Respiratory therapists (RTs) comprise a critical sector of allied health care, and the number of RTs continues to grow. With health care expanding from acute to chronic care, there is a strong impetus to manage patients on an out-patient basis. The importance of the RT in the prevention and management of chronic conditions and as part of a health-care team must not be underestimated. It is valuable to understand how RTs in practice view their future role and expectations of their profession.

\section{What this paper contributes to our knowledge}

This study has informed the current and future directions of the respiratory care profession in New York State. There was consensus for increasing the scope of practice of the RT, gaining reimbursement for services provided, advocating for competitive salaries with other allied health professions, and promoting a higher academic standard for the profession.

To prepare the RT workforce for the competencies needed to meet future health-care priorities, Becker et al, ${ }^{9}$ indicate that patient care may be improved by raising the minimum educational standard of RTs from associate-prepared to baccalaureate and beyond. Despite these indications, few educational programs are designed to achieve this goal. A recent Commission on Accreditation for Respiratory Care audit found that of 438 nationally accredited respiratory therapy programs, $374(85 \%)$ offer a $2-y$ degree, whereas only 61 4-y programs (14\%) award a baccalaureate degree. ${ }^{10}$ In New York State in 2016, there are 13 schools that offer respiratory therapy programs; of these, $10(77 \%)$ offer associate degree programs, whereas $3(23 \%)$ offer a bachelor of science degree. ${ }^{10}$

Seven states, including New York, are currently implementing a federally funded statewide initiative called the Delivery System Reform Incentive Payment (DSRIP). ${ }^{11}$ The goal of DSRIP is to address the healthcare needs and medical services to those on Medicaid and the uninsured by developing extensive healthcare systems involving multiple healthcare providers. ${ }^{12}$ It is important for RTs to be included within the DSRIP network of providers. The initiative of DSRIP is to provide improved patient care while increasing substantial savings. These goals will be achieved by decreasing emergency department and hospital utilization in a 5 -year period by 25 percent. ${ }^{13}$

Under DSRIP, of the $\$ 8$ billion invested in the Medicaid Redesign Team, the New York state governor has allotted $\$ 1.08$ billion toward Medicaid redesign purposes to support and strengthen behavioral health services, Home Health 
development, and to strongly capitalize in a long-term healthcare labor force. ${ }^{14}$ The DSRIP initiative has the potential to significantly impact the practice of respiratory care and the practice of health care in New York State, and could direct many RTs to work in out-patient settings. Since DSRIP is federally funded, this may encourage more states to participate, in an effort to improve the way medical care is delivered. As a result, those involved in the program may begin to see similar trends as those seen in New York State. Recognizing the shifting professional landscape, this study set out to understand current perceptions of RTs in New York State regarding professional roles and responsibilities.

\section{Methods}

The link to an online survey using SurveyMonkey was e-mailed on October 20, 2014, to 2,170 members of the AARC, in cooperation with the New York State Society for Respiratory Care and the New York Downstate Association for Respiratory Therapists. The survey was piloted with 6 academic RTs at Stony Brook University for content validity, logical flow, and overall clarity as well as to measure the time required for survey completion. Feedback from the pilot was used to adjust the logic and verbiage of the survey questions before data collection. Members of the research team encouraged survey completion using multiple approaches: an e-mail blast to all members of the New York State Society for Respiratory Care, speaking at the New York Downstate Association for Respiratory Therapists symposium about the importance of completing the survey, and reminder e-mail blasts sent on days 10 and 22 with cooperation from the New York State Society for Respiratory Care. The survey was closed on December 1, 2014.

The survey included 32 close-ended questions with branching logic based on the role of RTs as a direct care practitioner or administrator. The survey was organized along 5 major content areas: (1) participant characteristics, (2) staffing, (3) retention, (4) attrition, and (5) perceptions of the future of the profession. Samples of the survey items can be seen in Figure 1. Approval to conduct this study was provided by the Stony Brook University Committee on Research Involving Human Subjects in July 2014.

\section{Data Analysis}

The data were analyzed using SPSS 23.0 for Windows (SPSS, Chicago, Illinois). The data cleaning process resulted in the removal of 34 surveys with $>50 \%$ of data missing. Sample sizes varied because some respondents did not answer all questions, but respondents were included in the analysis if they answered $\geq 50 \%$ of the questions. Descriptive statistics were calculated for all study variables using frequencies, percentages, medians, and interquartile ranges, where appropriate. The Mann-Whitney $\mathrm{U}$ test and Kruskal-Wallis test were used to compare scores between 2 categories and 3 categories, respectively. An $\alpha$ level of .05 was used for all statistical tests.

\section{Results}

\section{Participant Characteristics}

Four hundred sixty-nine members participated in the survey for a response rate of $22 \%$ (469 of 2,170). After the data cleaning process, 34 incomplete surveys were removed, resulting in a final data set of 435 surveys. Table 1 shows the characteristics of the survey participants. The majority of respondents were staff therapists $(61 \%)$ currently employed in hospital settings (74\%) and working full-time in respiratory care. Over half of survey respondents $(61 \%)$ reported having a bachelor's degree or higher, and most (72\%) had $>15 \mathrm{y}$ of experience in the field of respiratory care.

\section{Staffing}

Most respondents (61\%) reported that their workplace was understaffed. Of the 182 who are responsible for hiring, more than half reported that they planned to hire $<3$ full-time equivalents and $<3$ part-time or per diem positions in the next $5 \mathrm{y}$. Only about one third reportedly expect to hire for $\geq 4$ full-time equivalent, parttime, or per diem positions in that time frame. When asked about hiring preferences in a potential RT, 38\% of hiring managers indicated that they had no preference, whereas $60 \%$ had preference relating to years of experience; $27 \%$ preferred new graduates, $46 \%$ preferred 1-4 y of clinical experience, and $27 \%$ preferred 5-10 y of experience.

Sixty-two percent of managers reported that the typical shift that RTs worked in their department was $12 \mathrm{~h}, 30 \%$ reported $8 \mathrm{~h}$, and $8 \%$ reported either $10 \mathrm{~h}$ or combinations of 8 and $12 \mathrm{~h}$. Most managers (70\%) reported that they expect this trend to continue.

Of 421 respondents, $23 \%$ indicated that they hold a second job. Of that group, the majority $(71 \%)$ were staff therapists, $15 \%$ were supervisors, $12 \%$ were associate directors or directors, and $2 \%$ were educators.

\section{Retention}

When asked what was most important to them as employees, $47 \%$ indicated salary, and $22 \%$ chose either scope of practice or room for growth. A Kruskal-Wallis test showed that there was no statistically significant difference in rating importance by position (director/supervisor, 


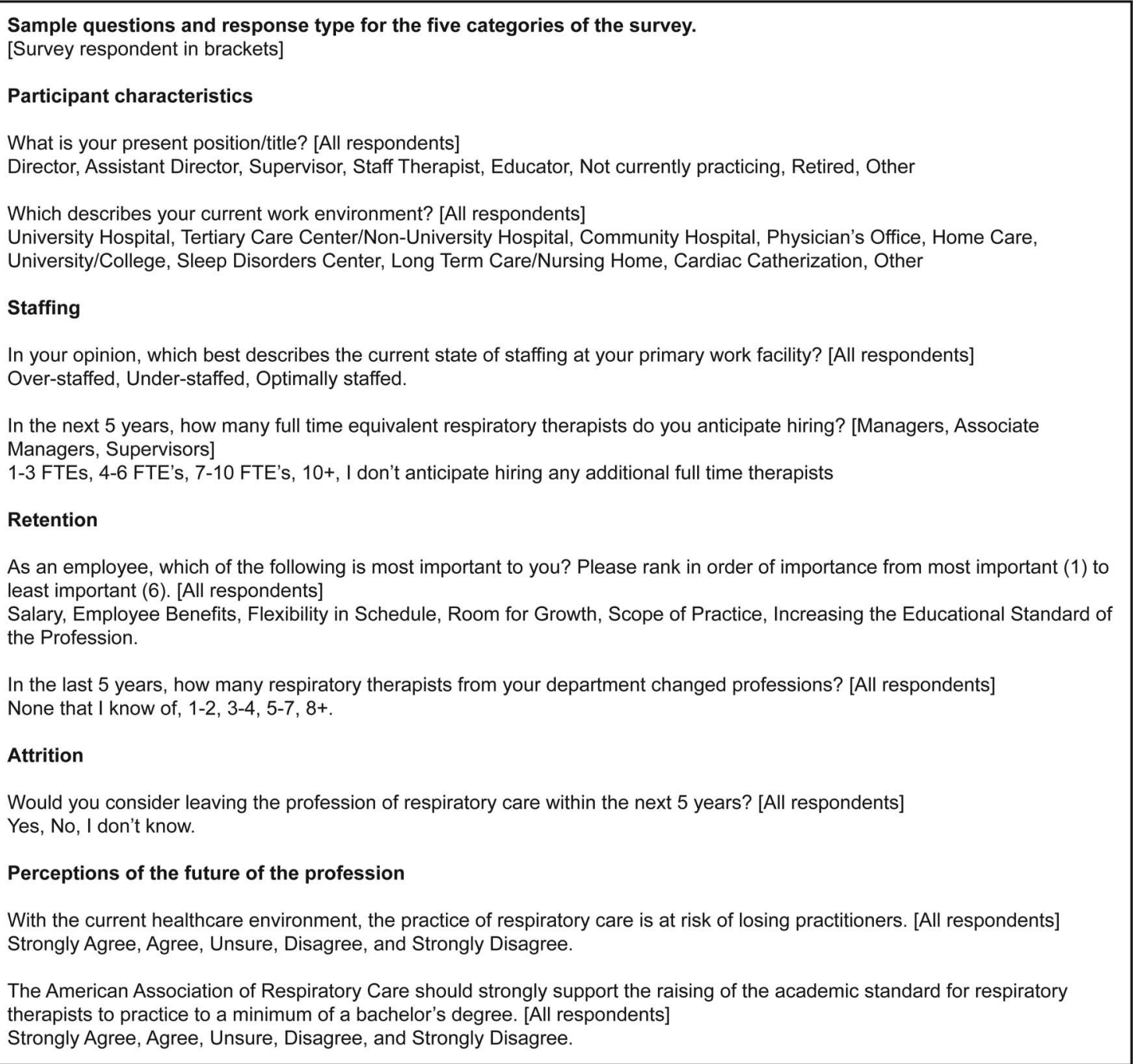

Fig. 1. Sample questions and response type for the 5 categories of the survey.

educator, and clinical staff) for salary $(P=.09)$, room for growth $(P=.82)$, or scope of practice $(P=.13)$.

The most important incentive for retention of RTs to the field was the development of a clinical ladder (growth/upward mobility), followed by an increased scope of practice. Of 420 respondents, $51 \%$ strongly agreed or agreed that there were opportunities to grow into a managerial or leadership role, and of 415 respondents, 325 (78\%) strongly agreed or agreed that it was important to remain in the profession of respiratory care. A KruskalWallis test showed that there was no statistically significant difference in agreement by educational attainment (less than bachelor's degree, bachelor's degree, graduate degree) about: importance to remain in the respiratory care profession $(P=.057)$, room for growth $(P=.82)$, or scope of practice $(P=.057)$.

\section{Attrition}

Of 421 respondents, 257 (61\%) acknowledged that in the last $5 \mathrm{y}$ they knew of RTs in their department who had changed professions, and 51 (20\%) of those reported knowing of $\geq 5$ people who had changed professions. When asked which health professions RTs are more likely to enter, given the choices of nursing, physician assistant, physician, leaving health care altogether, or other, the 409 respondents replying to the question predominately indicated nursing (33\%) and physician assistant (37\%). When asked whether they would personally consider leaving the profession within the next $5 \mathrm{y}$, of 421 respondents, $37 \%$ answered yes and $18 \%$ were unsure. Of those who would leave the profession, besides planning for retirement, the 2 most cited reasons were reported as (1) a limited ability for 
Table 1. Characteristics of Survey Participants

\begin{tabular}{|c|c|}
\hline Characteristics & $n(\%)$ \\
\hline \multicolumn{2}{|l|}{ Position/title } \\
\hline Staff therapist & $267(61)$ \\
\hline Director/associate director & $76(18)$ \\
\hline Supervisor & $55(13)$ \\
\hline Educator & $28(6)$ \\
\hline RT or RTT not currently employed & $9(2)$ \\
\hline \multicolumn{2}{|l|}{ Work environment } \\
\hline University hospital & $86(20)$ \\
\hline Tertiary care center/non-university hospital & $80(18)$ \\
\hline Community hospital & $156(36)$ \\
\hline Physician's office & $9(2)$ \\
\hline Home care & $26(6)$ \\
\hline University/college & $21(5)$ \\
\hline Sleep disorder center & $13(3)$ \\
\hline Long-term care/nursing home & $34(8)$ \\
\hline Other & $10(2)$ \\
\hline \multicolumn{2}{|l|}{ Degree } \\
\hline Associate's degree & $165(38)$ \\
\hline Bachelor's degree & $187(43)$ \\
\hline Master's degree & $75(17)$ \\
\hline Doctoral degree & $4(1)$ \\
\hline Other & $4(1)$ \\
\hline \multicolumn{2}{|l|}{ New York State licensed credentials } \\
\hline RT & $316(73)$ \\
\hline RTT & $114(26)$ \\
\hline Not applicable & $5(1)$ \\
\hline \multicolumn{2}{|l|}{ Level of experience } \\
\hline Less experienced $(0-5 \mathrm{y})$ & $63(14)$ \\
\hline Experienced (6-15 y) & $61(14)$ \\
\hline Very experienced $(>15 \mathrm{y})$ & $311(72)$ \\
\hline $\begin{array}{l}N=435 \\
\text { RT }=\text { respiratory therapist } \\
\text { RTT }=\text { respiratory therapy technician }\end{array}$ & \\
\hline
\end{tabular}

growth/limited scope of practice and (2) a lack of confidence in the future of the profession.

\section{Perceptions About the Future of the Profession}

When asked to rate the importance of clinical responsibilities to the future of the respiratory care profession, with 1 being most important and 5 being least important, the greatest number of the 415 respondents rated as 1 the ability to assess patients/develop a care plan and rated as 2 reimbursement for services as the most important factors, each with a median of 2.0 and interquartile range of 2.0.

The majority $(291,70 \%)$ strongly agreed or agreed that in the current health-care environment, the practice of respiratory care is at risk of losing practitioners. Overall, 266 of respondents (64\%) agreed that the AARC should support the raising of the academic standard for RTs to a

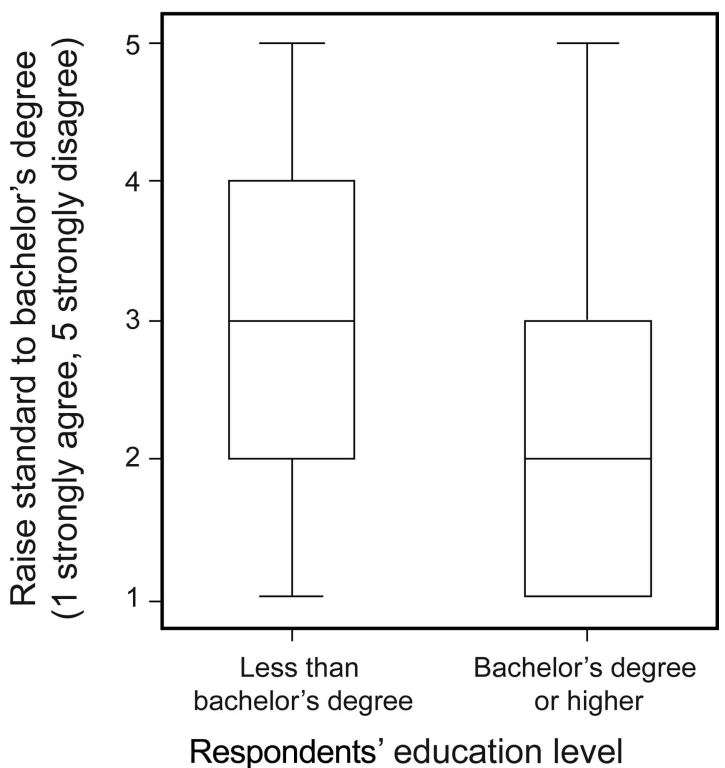

Fig. 2. Agreement that the American Association for Respiratory Care should support raising the academic standard to baccalaureate level, by subject education level. Boxes denote the first to the third quartile, center lines represent the median, and whiskers show overall variation of the responses. Respondents with a bachelor's degree or above were more likely to agree (median=2 [agree]) than those with less than a bachelor's degree (median $=3$ [unsure]).

minimum of a bachelor's degree. A Mann-Whitney U-test indicated that agreement was greater $(1=$ strongly agree, $5=$ strongly disagree) for those with at least a bachelor's degree or higher (median $=2$ ) than for those with less than a bachelor's degree (median $=3$ ), $P<.001$ (Fig. 2).

There was less agreement regarding a master's program in respiratory care. When asked whether a master's level program in respiratory care should be supported by the profession to increase the role of RTs in clinical practice, $176(42 \%)$ strongly agreed or agreed that it should, and 86 (21\%) were unsure. A Mann-Whitney U test indicated that agreement that the profession should support a master's level advanced practice designation was greater for those with at least a bachelor's degree (median $=2$ ) than for those with less than a bachelor's degree (median $=3$ ), $P<.001$. Of 415 respondents, 180 (43\%) strongly agreed or agreed that they would be likely to complete a master's level respiratory care program if it resulted in an increased scope of practice, and over three quarters (346, $83 \%$ ) agreed that it is important to be an active member of the AARC.

\section{Discussion}

This study assessed the extent to which New York State practicing RTs perceive their clinical and academic role, 
including opportunities and challenges to expanding their scope of practice. Twenty-two percent (22\%) of New York State Society for Respiratory Care member RTs responded, and most were staff therapists working in hospital settings with $>15$ y of experience. This demographic is similar to those of the 2009 and 2014 AARC Human Resource Surveys.

\section{Staffing}

Staffing issues are a concerning reality, as evident from the survey findings. Less than $40 \%$ of managers reported that they would hire $>3$ full-time equivalent, and $<30 \%$ expected to hire for $>3$ part-time or per diem positions in the next $5 \mathrm{y}$, despite the finding that the majority of respondents indicated that the facility they worked in was understaffed. Although staffing issues are complex and highly dynamic, especially with issues such as retirement and relocations, our data could indicate a challenging job market for RTs over the next few years. Moreover, since most managers held a hiring preference for at least $1 \mathrm{y}$ of experience in the field, with only about one quarter of them giving preference to new graduates, it appears that recent graduates of respiratory therapy programs may experience added difficulties in securing positions. According to the 2015 Commission on Accreditation for Respiratory Care data, average graduate job placement for New York RT educational programs was $83 \% .{ }^{15}$ Additionally, since most respondents (62\%) indicated that the typical shift in their organization was $12 \mathrm{~h}$, seeking additional employment is not only feasible, but may be necessary for economic reasons. In fact, approximately one quarter of participants indicated that they hold a secondary respiratory care position. If this percentage is extrapolated to the 6,483 licensed RTs in New York State, this would result in 1,620 positions that are held by RTs already working another job. This trend can have a dramatic impact on the available positions for new graduates. The AARC also makes note of this decline in available RT positions in their 2014 Human Resource Study. ${ }^{4}$

For respiratory care educational programs in New York State, these findings should be interpreted with caution. The results may reflect the sample who were mostly (74\%) working in hospital-based respiratory care departments. Additionally, there may be a potential shift taking place as a result of the Affordable Care Act, with a need to have more RTs practicing in the out-patient arena with increased autonomy and ability to clinically manage patient care. Since the role of the RT in the out-patient setting is currently limited, ${ }^{2,4}$ this shift would call for an increased scope of practice, reimbursement for services, and advances in respiratory care educational program curricula to meet this demand.

\section{Retention/Attrition}

Survey findings indicate that one of the most concerning factors for RTs currently practicing in the field was salary, consistent across position/title. Many identified this as one of the reasons that they would consider leaving the profession. These findings are consistent with the 2014 human resource study report, where approximately $25 \%$ of respondents indicated that compensation and benefits was an area that decreased their job satisfaction. ${ }^{4}$ The New York State Department of Labor Occupational Employment Statistics first quarter report shows that the mean salary for an RT in New York is $\$ 67,430$, and that for a respiratory therapy technician is $\$ 56,140 .{ }^{16}$ These salaries are approximately $15 \%$ less than similar allied health professions. In March of 2015, the New York State Department of Labor reported the mean salary for physician assistants as $\$ 101,690$, for occupational therapists as $\$ 79,960$, for physical therapists as $\$ 85,610$, and for registered nurses as $\$ 78,190 .{ }^{16}$ National statistics portray a similar trend. The 2014 United States Bureau of Labor Statistics reports that the national mean annual wage for an RT was $\$ 58,490 .{ }^{17}$ This reported salary is again less other allied health professions. Specifically, the United States Bureau of Labor Statistics reports the national mean annual wage for physician assistants as $\$ 97,280,{ }^{18}$ for occupational therapists as $\$ 80,000,{ }^{19}$ for physical therapists as $\$ 83,940,{ }^{20}$ and for nurses with an associate's degree as $\$ 65,470 .{ }^{21}$ This salary inequality among the allied health professions may also explain why many survey respondents report working an additional position, report that they would consider leaving the profession, and know of RTs who have chosen to transition to nursing or physician assistant professions.

\section{Future Directions}

In this study, practitioners identified 3 main issues instrumental to the sustainability and growth of the profession of respiratory care: (1) obtaining the ability to assess patients and develop a plan of care, (2) receiving reimbursement for services, and (3) obtaining the ability to write prescriptions. According to former AARC president, Frank Salvatore, "We need to assure that readmissions for COPD patients are reduced; that all asthma patients have access to their medications; that all pulmonary patients are able to have access to the specialized care delivered by RTs. This includes care beyond the walls of the hospital including telehealth." 22

The Medicare Telehealth Parity Act is a current key piece of legislation that is relevant to RTs in several key aspects: It covers licensed RTs as qualified telehealth practitioners, incorporates RTs into the Medicare statute, and adds coverage of remote patient management services, including COPD. The telehealth bill will provide the RTs 
with an advanced role in patient care and provide patients with a better availability to RT services. ${ }^{23}$ Services included under this act would include in-home technology and monitoring based on professional consultations, patient monitoring, patient training services, clinical observation, assessment, and treatment. The services and scope of practice provided by an RT will be based on medical assuredness, reimbursement policies, and an established timeline through regulatory guidelines in consultation with those involved with the patient's care. ${ }^{24}$ Receiving reimbursement for these valuable clinical services is an important step, and many survey respondents agreed that it plays a significant role in the viability of the profession for the future. To ensure reimbursement for these services, a bachelor's degree-prepared RT may be necessary, further justifying the need for a higher entry level academic standard for RTs.

The clinical expertise of an RT in the disease management of such disorders as asthma and COPD makes them ideal practitioners for expanded roles in the out-patient arena and can ultimately result in decreased readmissions and better outcomes for chronically ill cardiopulmonary patients. In fact, DSRIP's Department of Health projects currently include a variety of clinical practices that would offer ideal opportunities for RTs. Some of the projects taking place in New York State include the care transitions intervention model that aims to reduce $30-\mathrm{d}$ readmissions of chronic health conditions, the cardiovascular health project that seeks evidence-based strategies for disease management in high-risk/affected adult populations, the expansion of the asthma home-based self-management program, and a population-based health chronic disease prevention and management program..$^{25}$ According to the Kaiser Family Foundation, similar projects are being developed in other states. New York DSRIP programs, if successful, have the potential to be replicated across various other states by health-care policy makers. ${ }^{26}$

The effective management of patients with chronic disease would benefit from an advanced RT. Fuhrman and Aranson ${ }^{6}$ advocate for the RT's future role when they suggest that RT educators and appropriate physician specialists must work together to develop the scope of practice for the independent RT. An independent RT who is educated and credentialed appropriately can comply with this scope of practice, which is based upon the requirements of the physicians, their patients, and evidence-based medicine. RTs should be recognized similarly to other ancillary medical professionals under Medicare guidelines. ${ }^{6}$ With many pulmonologists approaching retirement age and indications of insufficient specialists entering practice, Keene advocates for an increase in education, competency assessment, and the future credentialing of RTs as physician extenders for pulmonologists. ${ }^{27}$

The findings from our survey supported the raising of the academic standard for RTs to practice to a minimum of a bachelor's degree. Recent literature has revealed similar support outside of New York State. In an article surveying Directors of Respiratory Therapy Departments nationally, it was found that close to three-quarters of the directors surveyed approved of a baccalaureate or graduate degree in order to succeed in their practice. ${ }^{28}$ At an AARC third task force conference addressing the roles and responsibilities of RTs, there was an agreement on the need for a baccalaureate degree as the minimum entry level educational standard for beginning respiratory care practice. ${ }^{1}$ The most recent AARC Education Position Statement encourages that respiratory care programs award a bachelor's or master's degree in respiratory care and mandate that the development of future RT educational programs, minimally, should be at the bachelor's degree level. ${ }^{29}$

Many allied health professions began as entry-level undergraduate prepared degrees. However, over the last 20 years, most have evolved into master's level or higher, whereas the respiratory care profession has not. Barnes points out that although the role of the RT has expanded a great deal over the last 40 years, there has been no change in the educational requirements of the graduate RT. Today, RTs treat patients with more complex conditions and perform more complex therapies compared to twenty years ago. To adequately prepare graduates, additional educational preparation is important to develop the skills to operate new medical devices, perform new techniques in therapy, and deliver medications. ${ }^{1}$

For respiratory care educational programs, changes to curricula that prepare future RTs for this expanded outpatient role in disease management would be needed. RTs could be involved in education to help patients manage their disease, including developing and monitoring a treatment plan. ${ }^{6}$ Additionally, RTs could play a larger role in the interpretation of sleep studies, in pulmonary function testing, and in specialty areas such as cardiopulmonary rehabilitation. The delivery of these advanced diagnostic and therapeutic services certainly justifies an increase in the academic preparation for achieving competence in the field. Encouraging RTs to obtain a baccalaureate degree or higher can serve to strengthen their versatility in adapting to different practice settings, improve their ability to communicate effectively, and facilitate their alignment with other allied health professions that have elevated academic standards. The AARC conducted a recent unofficial poll that found that the majority of approximately 80 respondents agreed that an advanced degree in respiratory care assisted them in advancing their career and provided personal career satisfaction. ${ }^{30}$

More recently, there have been discussions about the evolution of master's degree programs for the training of an advanced practice respiratory therapist. This study found that the most important reason reported for leaving the profession of respiratory care was a limited scope of prac- 
tice and lack of opportunities to grow. The finding that RTs with higher education were more likely to support a master's degree in respiratory care suggests that this is an important area for future growth of the profession. Keene et al, ${ }^{27}$ asked RTs and respiratory care educators about an advanced practice respiratory therapy program. The majority $(78 \%)$ indicated that they would rather remain in their profession, with advanced training and education, than move on to a physician assistant program.

The United States Bureau of Labor Statistics (USBLS) Job Outlook indicates that from 2012-2022, the projected growth of RTs is optimistic and faster than average for all occupations. ${ }^{3}$ It is encouraging to see that of 415 respondents, the majority $(325,78 \%)$ agreed that it was important to remain in the profession, regardless of their level of education. Furthermore, 346 (83\%) felt that it was important to be an active member of the AARC, recognizing that this national organization plays an influential role in providing direction for the future of the profession. It is imperative that RTs become more actively involved in both their national and statewide associations, encourage leadership in these associations, and advocate for positive change and growth to the profession of respiratory care.

\section{Limitations}

According to the New York State Education Department, when the survey was distributed, there were 5,433 licensed RTs and 1,050 licensed respiratory therapy technicians. ${ }^{5}$ Twenty-six percent of the respondents $(n=114)$ held a registered respiratory therapist (RTT) credential. This is higher than the percentage of RTTs licensed within New York State. However, this percentage is comparable with other similar surveys. ${ }^{31}$ As explained in a 2014 article by Smith et al, licensing in New York involves a 2-tier system. ${ }^{31}$ It is possible that RTTs could have successfully passed the NBRC RRT exam but may not have applied for an RT license in New York. In this survey, RT license data were collected (RT or RTT), but not the therapists' actual certified respiratory therapist and RRT credentials.

Only $33 \%$ of licensed professionals were members of the AARC at that time $(n=2,170)$ and would have potentially received the survey. The response rate of $22 \%$ may not be representative of the opinions of all members at large or nonmembers, although it too is comparable with other similar surveys. . $^{2,31,32}$ It is possible that respondents self-selected to participate and, thus, may have differed in some important ways from non-respondents. Most survey respondents possessed $>15 \mathrm{y}$ of experience in respiratory care practice and may have had a stronger motivation to participate in professionally related surveys. However, it is plausible that respondents may be similar to non-respondents. For example, our population sample with regard to academic preparation was comparable with the 2014 AARC Human
Resource Survey's random sample in the percentage of respondents holding an associate's degree (38\% vs 53\%), bachelor's degree ( $43 \%$ vs $31 \%$ ), master's degree (17\% vs $9 \%$ ), and a doctorate level degree (1\% in both). ${ }^{4}$ Although education level is only one characteristic, it is reasonable that our sample was similar to those who responded. Finally, errors in e-mail addresses may have resulted in some members not learning of the opportunity to participate.

Despite these limitations, this study has informed the current and future directions of the respiratory care profession in New York State. Future studies should include a national survey of RTs to assess perceptions regarding reimbursement for services, increasing the scope of practice of the RT, advocating for competitive salaries with other allied health professions, and promoting a higher academic standard for the profession. We also recognize the role of the AARC in reaching a greater number of RTs both locally and nationally to assess their perceptions for the future of the profession.

\section{Conclusion}

These data are useful to the respiratory care profession, notably for academic programs that must meet the need for a more highly prepared and skilled respiratory care workforce. The findings emphasize that viability of the profession in the current health-care environment calls for the evolution of a more autonomous RT who can be reimbursed for services and obtain salaries that are competitive with other allied health professions. The respiratory care profession will need to evolve and expand its current role in in-patient care as well as ensure inclusion in the out-patient arena. According to Myers, to remain competitive in this new health care environment, RTs must strengthen their position in the treatment of cardiopulmonary diseases by furthering their education. ${ }^{33}$ Increasing the scope of practice and the educational standards of the profession will increase the opportunity for growth in the field and strengthen the confidence that practitioners have in the future of the profession.

\section{ACKNOWLEDGMENT}

We thank Dr Jie Yang and the Biostatistical Consulting Core at the School of Medicine, Stony Brook University, for biostatistical consultation and review of the statistical analysis results.

\section{REFERENCES}

1. Barnes TA, Kacmarek RM, Kageler WV, Morris MJ, Durbin CG. Transitioning the respiratory therapy workforce for 2015 and beyond. Respir Care 2011;56(5):681-690.

2. Kocher N, Chapman, Susan, Dronsky, Marina. Respiratory Care Practitioners in California. San Francisco. CA: The California Endowment;2003:8. http://www.rcb.ca.gov/forms_pubs/ucsf.pdf. Accessed August 4, 2015.

3. United States Department of Labor. Occupational Outlook Handbook, Respiratory Therapists. Bureau of Labor Statistics. http:// 
www.bls.gov/ooh/healthcare/respiratory-therapists.htm. January 8 , 2014. Accessed August 6, 2015.

4. American Association of Respiratory Care. AARC Respiratory Therapist Human Resource Study 2014. Irving, Texas: AARC; 2014. http://www.aarc.org/resources/tools-software/aarc-respiratorytherapist-human-resource-study-2014/. Accessed August 4, 2015.

5. NYSED.gov. Respiratory therapy license statistics. Office of the Professions. http://www.op.nysed.gov/prof/rt/rtcounts.htm. July 1, 2014. Accessed November 1, 2014.

6. Fuhrman TM, Aranson R. Point: should Medicare allow respiratory therapists to independently practice and bill for educational activities related to COPD? yes. Chest 2014;145(2):210-213.

7. Bischoff EWMA, Hamd DH, Sedeno M, Benedetti A, Schermer TR, Bernard S, et al. Effects of written action plan adherence on COPD exacerbation recovery. Thorax 2011;66(1):26-31.

8. Spruit MA, Singh SJ, Garvey C, ZuWallack R, Nici L, Rochester C, et al. An official American Thoracic Society/European Respiratory Society statement: key concepts and advances in pulmonary rehabilitation. Am J Respir Crit Care Med 2013;188(8):e13-e64.

9. Becker EA, Nguyen XT. The current impact of entry-level associate and baccalaureate degree education on the diversity of respiratory therapists. Respir Care 2014;59(12):1817-1824.

10. Commission on Accreditation for Respiratory Care. 2014 report on accreditation in respiratory care education;2015:87. http://www. coarc.com/. Accessed December 2, 2015.

11. National Association of Medicaid Directors. NAMD issue brief on DSRIP; HCBS rule; actuaries ask for health insurance fee calculation guidance; NAMD fall conference. National Association of Medicaid Directors. http://medicaiddirectors.org/node/ 1007\#from-the-namd-desk. 2012. Accessed July 21, 2015.

12. Sheprow L. Stony Brook University Hospital-led Suffolk Care Collaborative launches new website. Stony Brook Newsroom. http:// sb.cc.stonybrook.edu/news/general/2015-0507-sbuh-led-suffolk-carecollaborative-launches-new-website.php. May 7, 2015. Accessed August 6, 2015.

13. Suffolk Care Collaborative. About DSRIP. Suffolk Care Collaborative. Suffolkcare.org. https://suffolkcare.org/AboutDSRIP. 2016. Accessed May 16, 2016.

14. Hamblin A, Sandman D, Helgerson J, Allen G, Chan P. The New York State DSRIP program: a model for reforming the Medicaid delivery system. December 2014. https://www.health.ny.gov/health_ care/medicaid/redesign/dsrip/docs/chcs_presentation_slides.pdf. Accessed August 6, 2015.

15. CoARC, Commission on Accreditation for Respiratory Care. Outcomes Data. http://www.coarc.com/36.html. Published 2015. Accessed March 23, 2016.

16. New York State Department of Labor. Occupational Wages. NYSDOL. http://labor.ny.gov/stats/lswage2.asp\#29-0000. March 2015. Accessed August 6, 2015.

17. United States Department of Labor. Occupational Employment Statistics; Occupational Employment and Wages, May 2014, 29-1126 Respiratory Therapists. Bureau of Labor Statistics. http://www.bls. gov/oes/current/oes291126.htm. May 2014. Accessed August 6, 2015.

18. United States Department of Labor. Occupational Employment Statistics; Occupational Employment and Wages, May 2014, 29-1071
Physician Assistants. Bureau of Labor Statistics. http://www.bls.gov/ oes/current/oes291071.htm. May 2014. Accessed August 6, 2015.

19. United States Department of Labor. Occupational Employment Statistics; Occupational Employment and Wages, May 2014, 29-1122 Occupational Therapists: Bureau of Labor Statistics. http://www.bls. gov/oes/current/oes291122.htm. May 2014. Accessed August 6, 2015.

20. United States Department of Labor. Occupational Employment Statistics; Occupational Employment and Wages, May 2014, 29-1123 Physical Therapists. Bureau of Labor Statistics. http://www.bls.gov/ oes/current/oes291123.htm. May 2014. Accessed August 6, 2015.

21. United States Department of Labor. Occupational Outlook Handbook, Registered Nurses. Bureau of Labor Statistics. http://www.bls. gov/ooh/healthcare/registered-nurses.htm. January 8, 2014. Accessed August 6, 2015.

22. American Association for Respiratory Care. AARC comments on Affordable Care Act ruling. AARC. http://www.aarc.org/aarc-commentsaffordable-care-act/. June 26, 2015. Accessed August 3, 2015.

23. American Association for Respir Care. PACT day efforts promote telehealth bill. AARC. http://www.aarc.org/pact-day-efforts-promote-telehealth-bill/. September 10, 2015. Accessed August 3, 2015.

24. American Association of Respiratory Care. AARC's legislative initiative for 2015: the Medicare Telehealth Parity Act. February 2015. http://www.aarc.org//app/uploads/2015/03/telehealth_faq.pdf. Accessed July 28, 2015.

25. Suffolk Care Collaborative. DSRIP projects. Suffolk Care Collaborative. http://suffolkcare.org/about/projects. 2015. Accessed August 3, 2015.

26. Gates A, Rudowitz R, Guyer J. An overview of Delivery System Reform Incentive Payment (DSRIP) waivers. kff.org. http://kff.org/ medicaid/issue-brief/an-overview-of-delivery-system-reformincentive-payment-waivers/. Accessed June 14, 2016.

27. Keene S, McHenry K, Byington R. Respiratory therapists as physician extenders: perceptions of practitioners and educators. Respir Care Educ Annu 2015;24(Fall 2015):19-27.

28. Kacmarek RM, Barnes TA, Durbin CG. Survey of directors of respiratory therapy departments regarding the future education and credentialing of respiratory care students and staff. Respir Care 2012; 57(5):710-720

29. American Association for Respiratory Care. Position statement: respiratory therapist education. November 2015. http://www.aarc.org// app/uploads/2014/10/respiratory-therapist-education.pdf. Accessed March 23, 2016.

30. American Association for Respiratory Care. Getting an advanced degree in respiratory care. AARC. http://www.aarc.org/careers/ career-advice/professional-development/getting-an-advanceddegree-in-respiratory-care/. 2015. Accessed August 4, 2015.

31. Smith SG, Brittelli J, Scott LB. Awareness of the 2010 guidelines implemented by the New York State Education Department for respiratory therapists in their role as clinical preceptors. Respir Care 2014;59(12):1846-1850.

32. Whitehead PB, Herbertson RK, Hamric AB, Epstein EG, Fisher JM. Moral distress among healthcare professionals: report of an institution-wide survey. J Nurs Scholarsh 2015;47(2):117-125.

33. Myers TR. Thinking outside the box: moving the respiratory care profession beyond the hospital walls. Respir Care 2013;58(8): $1377-1385$

This article is approved for Continuing Respiratory Care Education credit. For information and to obtain your CRCE

(free to AARC members) visit www.rcjournal.com

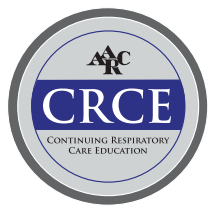

